\title{
ProfissionalizaÇÃo E MERCADO DE TRABALHO PARA PESSOAS COM DEFICIÊNCIA MENTAL NO BRASIL: O EMBUSTE NEOLIBERAL*
}

Adriane Giugni da Silva**

\section{RESUMO}

O presente ensaio tem como objetivo apresentar uma discussão sobre a profissionalização de pessoas com deficiência mental e a realidade do mercado de trabalho brasileiro. $\mathrm{Na}$ abordagem do assunto, pergunta-se: a profissionalização de pessoas com deficiência mental promove a sua inclusão no mercado de trabalho formal brasileiro? A fim de responder tal questionamento, procurouse discorrer sobre as mudanças impostas pelo mundo do trabalho, levando-se em consideração aspectos relacionados com o modo de produção capitalista que, no decorrer da história, requereu e exigiu novas formas de produção em virtude das diversas revoluções industriais e tecnológicas vivenciadas na sociedade do capital. Procedeu-se, também, à discussão de assuntos que se correlacionam, como as políticas públicas e a legislação, e discorreu-se sobre o reflexo dessas mudanças no processo de inclusão/exclusão social.

Palavras-chave: profissionalização; deficiência mental; exclusão social; trabalho; educação.

\section{INTRODUÇÃO}

O presente ensaio tem como objetivo pontuar alguns aspectos da educação especial no que concerne à profissionalização de pessoas com deficiência e às mudanças ocorridas no mundo do trabalho e encontra

* Artigo recebido em 5/5/2006 e aprovado em 15/8/2006.

** Doutora em Educação pela Universidade Estadual de Campinas; líder-coordenadora do Grupo de Pesquisa Políticas Públicas, Educação e Inclusão Social (GPPEIS); pesquisadora do Laboratório de Estudos e Pesquisas em Ensino e Diversidade (LEPED) da Unicamp; professora da Universidade Federal do Pará. E-mail: agiugni@superig.com.br 
correspondência em outro, relacionado aos diversos trabalhos de pesquisa desenvolvidos por esta pesquisadora em grupos de pesquisas dos quais é integrante, como o grupo de pesquisa Políticas Públicas, Educação e Inclusão Social (GPPEIS/Uepa) e o Laboratório de Estudos e Pesquisas em Ensino e Diversidade (Leped da Unicamp), nos quais investiga, por intermédio das linhas de pesquisa vinculadas, as políticas públicas relacionadas às pessoas com deficiência e ao modo pelo quais as instituições compreendem e procedem à formação profissional dessas pessoas para incluí-las socialmente, buscando-se caminhos alternativos que permitam melhor efetivação de tais procedimentos.

Não se tem a pretensão de esgotar a discussão, tampouco de solucionar problemas históricos e universais a partir de um artigo para publicação; contudo, acredita-se que, como outros profissionais e pesquisadores, seja possível contribuir para a discussão e o estudo da educação de pessoas com deficiência no Brasil, particularmente no que se refere à questão da relação educação/trabalho ou, ainda, à educação profissionalizante.

Com base em tais premissas, optou-se neste artigo por abordar algumas questões fundantes no que respeita à temática em questão, procedendo-se à discussão de aspectos relacionados à profissionalização, às políticas públicas, à legislação concernente à matéria e às mudanças ocorridas no mundo do trabalho, buscando-se compreender o reflexo dessas mudanças no contexto social brasileiro, no intuito de contribuir para a compreensão dos problemas vivenciados no Brasil referentes ao processo de exclusão-inclusão social desses sujeitos sociais.

Na seção intitulada "Profissionalização", apresenta-se os primórdios dos programas de treinamento vocacional e de profissionalização no Brasil, voltados para as pessoas com deficiência mental, identificandose sua origem nas instituições privadas, especificamente nas chamadas oficinas pedagógicas e protegidas. Na segunda, "Políticas públicas e legislação", assinala-se o caminho que percorreu a educação do deficiente mental desde os primórdios do século XVIII, além de se apontar alguns aspectos da legislação brasileira que amparam a educação da pessoa com deficiência mental. Na terceira, "Mudanças no mundo do trabalho", discorre-se sobre as alterações ocorridas no modelo de acumulação capitalista, relacionando-as às crises dos antigos modelos econômicos e ao processo de globalização. Na quarta e última seção, "Considerações 
finais: o reflexo dessas mudanças no contexto social brasileiro", evidenciam-se os reflexos das transformações ocorridas no interior das relações capitalistas de produção e as expressões dessas mudanças na educação da pessoa com deficiência na atualidade.

\section{PRofissionalizaÇÃo}

Desde a década de 1950, surgem no Brasil programas de treinamento vocacional e de profissionalização voltados às pessoas com deficiência mental. Esses programas originaram-se em instituições privadas de caráter filantrópico e assistencial, em escolas especiais ou similares. É a partir dessa década que se iniciam os trabalhos de capacitação e de exercício profissional, especialmente na Sociedade Pestalozzi do Brasil e nas Associações de Pais e Amigos dos Excepcionais (Apae), destinados aos aprendizes adolescentes e adultos nas chamadas oficinas pedagógicas e protegidas.

Essas modalidades de atendimento foram e ainda são predominantes na sociedade brasileira, especialmente quando a profissionalização se dirige à população com deficiência mental. As oficinas pedagógicas constituíram-se como proposta de "educação pelo trabalho", buscandose, a partir delas, a inclusão no mercado de trabalho, enquanto nas oficinas protegidas ocorria o chamado trabalho em regime especial, produtivo e remunerado. Outros tipos de oportunidades incluiriam desde internatos a trabalho em domicílio.

Em relação ao trabalho em mercado competitivo, este teria um grau parcial ou pleno de integração, dependendo do nível de alteração ambiental requerida. ${ }^{1}$ Por sua vez, as oficinas passaram a atuar em diferentes tipos de atividades, entre as quais se incluem reparos, prestação de serviços externos, cultivo de hortas, fabricação de itens próprios, além da produção entre instituição e empresas por meio de subcontratos ajustados.

As atividades desenvolvidas em oficinas protegidas ou abrigadas já existem há quase meio século. Entretanto, poucos são os estudos avaliativos de tais programas, bem como de outras atividades e ações desenvolvidas pelas instituições especializadas. Nesse particular é importante frisar que a maior parte das publicações disponíveis tem o caráter de divulgação institucional, não havendo, portanto, algum tipo de avaliação externa, descomprometida e isenta de quaisquer interesses ou 
influências. Somente a partir da década de 1980 surgem alguns artigos e algumas teses que auxiliam na percepção, ainda que parcial, de algumas atividades desenvolvidas na área, resgatando propostas e visões expressas por profissionais e por egressos dos programas.

Os escassos estudos sobre as condições de funcionamento das oficinas pedagógicas, abrigadas ou protegidas, apresentam uma realidade pouco animadora cuja justificativa dá-se em função da ocorrência de alguns problemas, tais como as crises financeiras institucionais, e do próprio país, isolamento do mundo externo, especialmente do próprio mundo do trabalho, subcontratos desfavoráveis para os aprendizes/ trabalhadores, inadequação/rigidez dos programas com relação às características da população institucionalizada, entre outras. Percebe-se que estão presentes as contradições resultantes do desafio de compatibilizar as atividades do ensino com aquelas da produção, além de conciliar as necessidades pessoais do aprendiz/trabalhador e as necessidades do mercado. ${ }^{2}$ Dessa forma, não se tem clareza dos reais benefícios ou dos beneficiários da profissionalização, uma vez que "ser egresso de uma instituição profissionalizante dificulta a integração [...] [que] é o objetivo final das mesmas instituições". ${ }^{3}$

É importante notar que a questão da profissionalização está no centro de uma articulação assumida entre trabalho e inclusão/exclusão social. Entendem alguns autores ${ }^{4}$ que a formação profissional e o desempenho de uma atividade produtiva é direito do cidadão que possui deficiência, constituindo-se esta em estratégia principal, senão a única, para sua inclusão. Tanto as ONGs quanto a literatura especializada acerca do tema, em sua quase totalidade, apresentam semelhanças em relação ao discurso ideológico quando preconizam que a pessoa com deficiência mental é dotada de capacidade para se profissionalizar, produzir e se adaptar como força de trabalho ao mercado, tornando-se assim um sujeito útil à sociedade.

A despeito dessa visão, defendida por alguns autores que estudam o tema, entende-se que o trabalho protegido ou acompanhado e a profissionalização não podem ser reconhecidos como um fator de equalização entre pessoas consideradas não-deficientes e pessoas com deficiências. Isto porque, embora as pessoas com deficiência possuam seus direitos, inerentes à sua natureza de sujeitos sociais, em função de suas especificidades biológicas, são pessoas "diferentes", ou seja, 
apresentam limitações que lhes são próprias e, por este motivo, não podem concorrer de forma igual com os indivíduos "ditos normais".

Compreende-se assim que tal discurso serve apenas para reforçar a segregação e a exclusão do mercado de trabalho, uma vez que ao deficiente é requerido e exigido, por parte do contratante, desempenho igual àquele que não possui deficiência. Ainda em relação a esse aspecto, deve ser ressaltado que o discurso de eqüidade com referência a oportunidades, apesar das especificidades biológicas próprias das pessoas com deficiência, induz à crença de que, se todos têm as mesmas oportunidades de acesso, são responsáveis pelo seu próprio fracasso ou sucesso, assim como se constituem em sujeitos iguais perante a sociedade, eliminandose de uma só vez, e de forma nefasta, as especificidades biológicas, os antagonismos de classe e as desigualdades historicamente estabelecidas pelo capital.

Outro complicador neste início de novo século é a "nova" forma de inclusão/exclusão social presente na contemporaneidade. O capital é detentor de grande capacidade de se metamorfosear, e esta é mais uma de suas formas de dominação. O início deste novo século registra situações dialéticas em que as sociedades apresentam simultaneamente as possibilidades de inclusão e de exclusão social. A primeira - inclusão - está relacionada à questão cultural/educacional em que as massas da população, com ou sem deficiência, são absorvidas por intermédio da educação, da mídia e da lógica do consumismo individualista no interior do mercado capitalista. A segunda - exclusão -, ocasionada em função de suas condições socioeconômicas, desloca a massa populacional com ou sem deficiência da sociedade, gerando ao mesmo tempo o processo dialético de inclusão/exclusão social. ${ }^{5}$ Percebe-se, portanto, que os problemas vão se aglutinando, ora relacionados à questão específica da deficiência, ora à especificidade do mercado competitivo, ora ainda aos dois fatores concomitantes.

Além destas questões, outra importante a ser abordada está relacionada à visão de que a pessoa com deficiência mental, após sua inclusão no mercado de trabalho, chega a uma etapa final de seu processo educativo. Nesse particular, compreende-se que o referido entendimento é, no mínimo, equivocado, pois na atual realidade imposta pelas mudanças ocorridas no mundo do trabalho, todos necessitam de formação continuada, requerida e exigida progressivamente pelo capital. Tal fator reveste- 
se de maior importância no que respeita à pessoa com deficiência mental, uma vez que, na maioria das vezes, há a necessidade (ainda que temporária) de um acompanhamento continuado como forma de orientação para o desenvolvimento de suas atividades, embora deva ser ressaltado que há casos em que pessoas com deficiências, ao serem inseridas no mercado de trabalho, não mais necessitam de nenhum acompanhamento externo sistematizado, desempenhando de maneira satisfatória suas tarefas, e a elas se "adaptando", uma vez que tais funções representam na sua quase totalidade a reprodução de tarefas pautadas em um modelo taylorista-fordista de produção.

Outro aspecto que deve ser enfatizado é o fato de que alguns estudos no Brasil ${ }^{6}$ apontam para ausência de um entendimento comum sobre a natureza da deficiência mental, que permitisse aclarar o sentido da solução oferecida pela formação profissional, bem como a ênfase que o discurso sobre profissionalização empresta às razões de ordem econômica no que diz respeito à redução de custos sociais propiciada pela capacitação da pessoa com deficiência.

Exercer uma atividade produtiva, uma atividade que resulta em um bem concreto, um trabalho, é de grande importância para a vida de todos os seres humanos, não apenas no que concerne ao aspecto financeiro, mas também em relação à possibilidade de conferir às pessoas envolvidas independência em termos sociais e pessoais, ou seja, inclusão social. O trabalho deve ser uma fonte de prazer e satisfação para o sujeito, além de propiciar-lhe as condições de sobrevivência, garantindolhe renda e manutenção de consumo, pois, como afirma Marx, "não é possível libertar os homens enquanto eles não estiverem completamente aptos a fornecerem-se de comida e bebida, a satisfazerem as suas necessidades de alojamento e vestuário em qualidade e quantidade perfeitas". ${ }^{7}$ Nesse sentido, a profissionalização deve ser entendida como uma necessidade do homem, propiciando-lhe o exercício de uma atividade produtiva que lhe possibilite desenvolver um trabalho no meio em que vive, considerando-se suas condições culturais e diferenças individuais.

Torna-se assim relevante o questionamento de alguns estudiosos que evidenciam a necessidade de buscar a textualidade histórica para discutir questões inerentes à deficiência mental e à profissionalização, em que "a questão dos limites da deficiência mental confunde-se de maneira acentuada com as questões de ordem socioeconômica e de fracasso escolar". ${ }^{8}$ 
Necessário se faz ainda proceder a reflexões constantes em relação ao trabalho que deve ser desenvolvido junto às pessoas com deficiência, pois, como se sabe, a presença de limites é uma constante na vida de todos os seres humanos, e o que se coloca é sua graduação ou diversificação. Cada pessoa apresenta pontos intelectuais mais limitados em relação a uma área ou outra, além de haver limitações também no plano físico, social, afetivo e econômico. A conscientização de que o limite existe em relação a todos deve ocorrer a fim de que os limites maiores, em termos intelectuais, possam ser mais bem aceitos na sociedade competitiva, especialmente em relação ao mundo do trabalho, que representa a auto-realização do ser humano.

A situação de trabalho torna-se ainda mais complexa quando o sujeito que vive é uma pessoa que possui deficiência mental. Isto porque o número de serviços de atendimento específico de profissionalização para esse grupo de pessoas é cada vez mais reduzido. Nesse contexto, a situação social do deficiente, na sociedade que estimula o consumismo e o lucro, é bastante ambígua, pois de um lado está a sociedade que objetiva altos lucros por meio da racionalização do trabalho e de outro a sociedade que enfatiza a necessidade de preparação satisfatória de mão-de-obra do deficiente para ser absorvida por esse mesmo mercado de trabalho.

No contexto legislativo, apesar das garantias constitucionais brasileiras assegurarem alguns direitos das pessoas com deficiência, no que concerne ao deficiente mental o legislador infraconstitucional não especifica formas de garantias diferenciadas para os diferentes níveis de deficiências. Em decorrência, quando da contratação, o agente contratante opta, na maioria das vezes, por deficiências que, na sua avaliação, efetuada de modo leigo, considera menos dispendiosa, assim como procura se certificar de que o trabalho seja desenvolvido por alguém menos comprometido mentalmente, ou seja, o contratante, entre as diversas deficiências, exclui ainda mais aqueles que já são tão excluídos socialmente - os deficientes mentais. No que diz respeito ao direito ao exercício do trabalho, há legislações específicas que tratam da pessoa com deficiência, como é o caso da Lei n. 8.213/91. ${ }^{9}$ Não há, entretanto, um regime especial de trabalho, o que dificulta a inserção da pessoa com deficiência no mercado de trabalho formal.

Ressalte-se que não se pretende defender privilégios para pessoas com deficiência mental; contudo, é de conhecimento de todos, especialmente dos pesquisadores que estudam essa parcela da população, que, 
diante da obrigatoriedade de se contratar, o empregador vai selecionando e limitando mais e mais a deficiência, o que significa que, entre os deficientes habilitados e reabilitados, os menos comprometidos serão os contratados. Nessa linha de análise, as pessoas com deficiência mental tornam-se cada vez mais excluídas e marginalizadas, seja pela sociedade que se considera desprovida de qualquer deficiência, seja por aqueles que apresentam deficiências distintas da mental.

Além disso, há no Brasil uma concepção do empregador, de forma geral, de que as pessoas com deficiências são onerosas ao mercado de trabalho, uma vez que dependem, em alguns casos, de adaptações ao ambiente ou mesmo de acompanhamento profissional. A conseqüência mais patente dessa realidade e da quase inexistência de regras que regulamentem a contratação compulsória pelo mercado de trabalho formal de pessoas com deficiência mental é a utilização de subterfúgios para não empregarem essas pessoas, tais como convênios com associações representativas de assistência, além da utilização de empresas terceirizadas.

As diferentes perspectivas de avaliação dos programas desenvolvidos pelas oficinas criam um quadro bastante pessimista em se tratando da autonomia dos chamados aprendizes. Não é pretensão deste trabalho negar e/ou desvalorizar as várias contribuições conseguidas pelas instituições de caráter privado que trabalham com o sistema de oficinas junto ao deficiente mental. Pretende-se apenas apontar as enormes dificuldades, vivenciadas pelos deficientes, em assegurar sua inserção social no mercado de trabalho a partir dos programas existentes. Outrossim, vale ressaltar que determinados programas, por causa de seu caráter segregador e marginalizador, necessitam ser reavaliados, embora se saiba que os problemas não se esgotam simplesmente pela sua qualidade duvidosa.

A profissionalização não é uma medida a ser tomada aleatoriamente, mas deve envolver levantamento de dados concretos, tanto em relação ao próprio deficiente quanto em relação à comunidade. Entretanto, se as alternativas disponíveis não forem adequadas, é preciso que uma nova proposição seja formulada com base nos dados disponíveis. A profissionalização da pessoa com deficiência mental é viável desde que existam alternativas possíveis na prática. Essas alternativas não devem expressar uma simples e casual oportunidade de encaminhamento, mas 
uma ação resultante de reflexão e análise objetiva de cada alternativa em relação às possibilidades reais de trabalho do deficiente mental.

Retornando à questão mais ampla da deficiência e do trabalho, considera-se importante sinalizar alguns aspectos da legislação que serão apresentados na próxima seção.

\section{PoLÍTICAS PÚBLICAS E LEGISLAÇÃO}

A literatura que trata questões concernentes à educação especial, sobretudo em relação à deficiência mental, remonta ao século XVIII, especialmente nos Estados Unidos e em alguns países da Europa.

O século XIX caracterizou-se como o das instituições residenciais, em sua primeira metade, que se fundamentavam em um modelo de "tratamento" conhecido como "medicina moral". Este método constituíase de treino psicomotor por meio de imposição de hábitos regulares e freqüentes, experiências concretas, rotinas, aliados à crença na capacidade de aprender.

Nas últimas décadas do século XIX, surgem perspectivas diferentes da sua primeira metade. Nesse período, ocorre a descrença na recuperação do deficiente mental, e o trabalho desenvolvido nas instituições passa a ser visto, notadamente, como forma de auxílio às próprias instituições e não propriamente aos deficientes. Além disso, a população atendida deixa de ser a mais abastada, que procura formas de cura, para dar lugar àqueles de menor renda, os delinqüentes, os deficientes mais graves, os considerados loucos e outros.

Pode-se dizer assim que as relações sofreram "metamorfoses", ${ }^{10}$ isto é, passou-se de um momento em que se buscava a cura para um outro em que se privilegiou a custódia e a assistência para casos de violência. Observa-se nesse período o aumento da segregação sob a forma de um discurso ideológico de assistência e de proteção.

No final do século XIX e início do século XX, surge o movimento chamado "eugênico". ${ }^{11}$ Esse período, caracterizado pela suposição da transmissão hereditária da deficiência mental, gera maior isolamento e institucionalização.

A institucionalização que se amplia é proveniente das pressões da urbanização capitalista e das condições de emprego/desemprego que, segundo Braverman (1987, p. 238), cria "um novo extrato de desem- 
pregados e dependentes", gerando um aumento de "doentes mentais" ou "deficientes". Assim, Braverman se expressa:

o maciço aumento das instituições que se estendem de todos os modos, das escolas e hospitais de um lado, a prisões e manicômios de outro, representa não precisamente o progresso da medicina, da educação ou da prevenção do crime, mas a abertura do mercado apenas para os "economicamente ativos" e em "funcionamento" na sociedade. (1987, p. 238)

Ao mesmo tempo em que a vida social e familiar da comunidade é enfraquecida, pois as relações se tornam mais frias e distanciadas em razão das necessidades impostas pelas novas relações sociais e de trabalho, há o aumento das instituições que passam a responder pelas necessidades e urgências da população. Por influência desta nova demanda social, cada vez menos apta para tratar uns dos outros, mais institucionalizada,

amplia-se enormemente: a proporção dos "doentes mentais" ou "deficientes", os "criminosos", as camadas pauperizadas na parte baixa da sociedade, todos representando variedades de desmoronamento sob as pressões do urbanismo capitalista e as condições de emprego ou desemprego capitalista. (BRAVERMAN, 1987, p. 238)

Nesse contexto de ampliação de serviços, surgem no Brasil as diversificações de deficiências, até então não identificadas, notadamente nas áreas de desenvolvimento intelectual, de linguagem e socioemocional. Novos modelos de atendimento e grandes campanhas, dirigidas às diferentes categorias de deficiência por parte do poder público, são articuladas. As instituições de cunho filantrópico-privadas começam a aparecer.

A partir da década 1920, surgem algumas instituições para deficientes mentais, constituindo-se em número de sete ao final da década. A Sociedade Pestalozzi é fundada por Helena Antipoff em 1932 e, mais tarde, surgem mais cinco instituições. Segundo Jannuzzi (1985), ao final do ano de 1935, havia vinte e duas instituições no Brasil para o atendimento de deficientes mentais.

Como se pode ver, até esse período, as políticas de atendimento ao deficiente mental são praticamente inexistentes. As pessoas com 
deficiência mental somente ocupam um espaço importante na história mais recente da Educação Especial no Brasil, com o estabelecimento de políticas públicas destinadas a essa população. Em 1954, surge a primeira Apae, fundada na antiga Guanabara, capital do Brasil na época, hoje Rio de Janeiro. ${ }^{12}$ As Apaes passam então a dominar o espaço político relativo à cobrança de políticas públicas para atender às pessoas com deficiência mental. Com a proliferação dessas instituições e sua influência política, o governo federal, a partir da década de 1960, inicia um processo de centralização administrativa e de coordenação política.

Contudo, apesar da legislação brasileira desde os anos 60 procurar definir com maior clareza o papel do Estado na formulação de políticas públicas destinadas a esse segmento da população, verifica-se na execução dessa legislação elementos de contradição e ambigüidade.

De um lado, há o entendimento de que a criação de uma legislação específica para deficientes mentais, em certa medida, pode resultar em um aumento da segregação e estigmatização por parte de aparatos institucionais criados para "integrarem" o deficiente mental ao mundo social e, conseqüentemente, ao mundo da produção, e, de outro, a crença de que a referência legal é um instrumento mínimo que assegura o atendimento aos direitos básicos dos deficientes.

No que concerne ao aspecto legislativo é importante ressaltar que grande parte da legislação aplicável ao tema em discussão surgiu em decorrência dos reclamos efetuados por integrantes de instituições de cunho privado (em sua maioria pais e familiares de pessoas com deficiência), os quais, no exercício das atividades inerentes à defesa dos interesses dessa população, viram-se tolhidos pela quase inexistência de diplomas legais aptos a propiciarem o exercício de tais direitos.

Percebe-se, assim, que as políticas públicas voltadas às pessoas com deficiência foram decorrentes das demandas do setor privado, tendose, portanto, dois campos bastante diferenciados no que respeita ao atendimento às pessoas com deficiência no Brasil: o privado e o público. O privado caracterizou-se pela multiplicação e consolidação de ações de caráter assistencial, assumindo responsabilidades de competência do Estado, por omissão deste. Já o público desenvolveu-se mediante o aumento do atendimento de classes especiais, especialmente para deficientes mentais, junto a escolas públicas.

Mas é a partir dos anos 70 que surgem em cena formulações mais detalhadas de políticas públicas voltadas ao atendimento dessa população. 
Nesse período, há uma intensificação da institucionalização da Educação Especial com a elaboração dos planos setoriais de educação, configurando-se em uma política de nível escolar, definidos pela Lei n. 5.692/ 71 , que prevê o tratamento especial para "os alunos que apresentarem deficiências físicas ou mentais [...] e os superdotados". ${ }^{13}$ Esta lei regulamentava os níveis de atendimento especial dos currículos e apresentava sugestões à formação docente.

Entretanto, somente com o advento do I Plano Setorial de Educação (1972-1974), a Educação Especial constituiu prioridade. É nesse momento que é fundado o Centro Nacional de Educação Especial (Cenesp), vinculado ao MEC, com o objetivo de centralizar e coordenar as ações de política educacional para as pessoas com deficiência. Esse período caracterizou-se como um momento de reestruturação de Educação Especial nos aspectos políticos e legais.

O Cenesp procurou centralizar todas as ações da Educação Especial até 1986, articulando politicamente com outros setores educacionais, privados e públicos recursos de natureza financeira e técnica. Nesse mesmo ano, foi criada a Coordenadoria para Integração da Pessoa Portadora de Deficiência (Corde), junto à presidência da República, para coordenar assuntos relativos ao portador de deficiência. Criou-se também nesse ano, em substituição ao Cenesp, a Secretaria de Educação Especial (Sespe), que foi extinta em março de 1990, passando suas atribuições à Secretaria Nacional de Educação Básica (Seneb). Nesse mesmo ano, surge o Departamento de Educação Supletiva e Especial (Dese), possuindo competências específicas em relação à Educação Especial. Em 1992, a Secretaria de Educação Especial (Seesp) reaparece vinculada ao Ministério de Educação e do Desporto, permanecendo com praticamente as mesmas atribuições e competências até hoje.

Apesar da existência de políticas públicas direcionadas à pessoa com deficiência, elaboradas pelo MEC, por intermédio atualmente da Seesp, todas as mudanças implementadas pelo Estado não se refletiram em melhorias substantivas para a pessoa com deficiência mental, haja vista a crise estrutural que se instalou no país. Se há ou não vontade política para efetivamente fazer-se valer os direitos conclamados legalmente como iguais a todos, o certo é que nem todos no país têm esses direitos de fato. No espaço aberto, estimulado e provocado por projetos falaciosos e embustes políticos, reforçam-se às desigualdades e 
de maneira consciente. Apesar de ideologizada, há o reforço às formas assistenciais, que nos dias de hoje

encontram terreno fértil para sua proliferação, fato que se encontra agravado (com os repasses de recursos para as instituições privadas - ONGs) [...] já que a ausência de consciência crítica impede um posicionamento que desvelaria as relações implícitas no que é considerado deficiência e do direcionamento que possam tomar as propostas educacionais e políticas relacionadas a ela. (DA Ross, 1982, p. 26)

Verifica-se, assim, a prevalência do atendimento elitista às crianças oriundas de classes médias, cabendo a tais instituições o poder político para conduzir as políticas da Educação Especial no país. Com o agravamento das políticas neoliberais que reforçam o surgimento de ONGs e serviços voluntários, transfere-se à sociedade civil a responsabilidade da formação/educação dos excluídos sociais, situando-se neste grupo as pessoas com deficiência.

Apesar desse quadro em que está inserida a Educação Especial no país, as contradições legais permanecem, pois, mesmo considerandose os dispositivos legais expressos na Constituição Federal, nas constituições estaduais e municipais, no Estatuto da Criança e do Adolescente, na Lei n. 7.853/89 e outros mais, em nossa realidade esses aparatos legais não garantem a implementação de fato dos direitos que pretendem assegurar, tampouco instituem novas práticas.

Essa realidade também pode ser visualizada quando se trata das questões relacionadas ao trabalho ou, mais especificamente, à inserção/ inclusão da pessoa com deficiência no mercado formal de trabalho. $\mathrm{Na}$ seção a seguir, serão feitas algumas considerações a esse respeito.

\section{MudAnÇAS NO MUNDO DO TRABALHO}

Os países capitalistas desenvolvidos conheceram ao final da Segunda Guerra Mundial, nos trinta anos que se seguiram, um nível de crescimento socioeconômico sem paralelo na história da humanidade. Este sucesso pode ser atribuído ao êxito das políticas macroeconômicas de sustentação da demanda efetiva, que foram inspiradas na teoria econômica keynesiana. As instabilidades cíclicas da economia capitalista 
foram equacionadas, sobretudo com instrumento de política fiscal, gerando crescimento com pleno emprego, salários reais em elevação e ausência de inflação.

Associado às políticas macroeconômicas keynesianas, consolidouse, do ponto de vista microeconômico, o paradigma industrial nascido com a segunda revolução tecnológica, ${ }^{14}$ de produção e consumo em massa de produtos padronizados. Esse paradigma taylorista-fordista, ou simplesmente chamado de fordismo, baseava-se na produção fabril em série e de grande escala. Em seu livro Princípios de administração científica, Taylor recomendava que as tarefas a serem executadas fossem divididas em operações simples, rotineiras e minuciosamente prescritas pela gerência.

As funções intelectuais de administração eram rigidamente separadas das funções de produção manuais. O emprego extensivo, de mão-de-obra não-qualificada, era assim permitido e estimulado. Pouco depois, Henry Ford introduzia a linha de montagem no processo de produção, possibilitando a fabricação em massa de produtos padronizados com produtividade crescente, que permitiu queda nos preços dos bens, elevação dos salários reais e intensificação do consumo. Os ganhos elevados de produtividade, repassados para os salários, permitiam que o acesso aos bens de consumo se generalizasse, integrando ao mercado a grande maioria da população. Produção em massa, emprego em massa e elevação real de salários era o tripé da virtuosidade econômica do fordismo.

O conceito fordismo, ${ }^{15}$ como paradigma industrial, foi assim apresentado: um conjunto de métodos de produção fundamentado em seqüências lineares de trabalho fragmentado e simplificado; linhas de montagem; longas horas de trabalho manual rotinizado; inexistência de controle por parte do trabalhador sobre o projeto, o ritmo e a organização do processo de produção; equipamentos especializados com baixa flexibilidade; comando fortemente hierarquizado do processo de trabalho; produção em massa, buscando ganhos elevados e escalonados; mercado de consumo de massa. ${ }^{16}$

À política econômica keynesiana e ao paradigma industrial fordista vieram somar-se a política social do Estado capitalista. A formação do welfarestate completava a parceria bem-sucedida keynesianismo/ fordismo. As despesas sociais estimulavam a demanda efetiva e minimizavam as tensões políticas e trabalhistas. $\mathrm{O}$ welfarestate consistia no 
financiamento público de gastos sociais destinados à educação, à saúde, à previdência e à assistência social, ao seguro-desemprego, à habitação e aos transportes.

A partir de meados da década de 1970, a economia keynesiana e o modelo do welfarestate começaram a dar sinais de esgotamento - a crise do welfarestate. Suas primeiras manifestações vieram com a rápida elevação do déficit público nos países industrializados. ${ }^{17}$ e foi acompanhada do aumento das taxas de juros e da dívida pública. A crise também se manifestou por meio da queda da produtividade da mão-deobra, da queda da eficiência dos investimentos públicos, da perda de capacidade de poupança da economia etc. Os países industrializados passaram a conviver com o fenômeno da recessão econômica e com a inflação em alta.

A excessiva divisão do trabalho e a constante elevação do ritmo de produção causaram grande insatisfação junto aos trabalhadores que criaram movimentos de resistência, elevando o descontentamento com o trabalho, aumentando o absenteísmo, a rotatividade e as falhas na produção, comprometendo, dessa forma, o crescimento da produtividade.

A baixa produtividade e os movimentos em descendência provocaram redução salarial e comprometeram a extensão do mercado. Com o fim do crescimento estável do mercado de consumo, o capital fixo de grande escala, composto de equipamentos rígidos, passou, segundo Harvey (1994, p. 135), a ser inadequado para enfrentar as exigências de mercados de consumo, agora variantes. Abalaram-se, assim, os pilares do modelo fordista.

A inserção da economia brasileira no modelo de desenvolvimento industrial capitalista, nascido com a segunda revolução tecnológica, deuse tardiamente. Ela teve início nos anos 30 e até os anos 50 era ainda incipiente. Entre os anos 50 e 60, a economia intensificou-se, mas, somente no período de 1968 a 1980, foi consolidada. Ao final da década de 1970, o Brasil configurava-se em uma grande economia industrial altamente integrada e diversificada. A renda per capita nesse período aumentou $80 \%$, segundo Velloso e Albuquerque (1994, p. 33), elevando, em alguma medida, a renda real por habitante, haja vista que a enorme concentração de renda existente não cresceu na mesma proporção.

Do início dos anos 30 até final dos anos 70, a industrialização brasileira consolidou no país um mercado de trabalho formal, o que garantiu o surgimento de ampla classe operária e de segmentos sociais 
médios assalariados. "O processo de industrialização conformou um mercado nacional de trabalho urbano e surgiram novas formas de ascensão social para parcela da força de trabalho" (DiEESE, 1994, p. 25).

Segundo Velloso (1994), ao final dos anos 70, deu-se início à formação de um mercado de consumo de massa com grande expansão do emprego, inclusive do emprego feminino, e aumento nos salários reais. Observa-se que esse "mercado de consumo de massa" excluiu uma grande parcela relativa da população brasileira.

Silva (1993) admite que a idéia de fordismo no Brasil seja de natureza controvertida e identifica o caso brasileiro como fordismo restrito $e$ autoritário. ${ }^{18}$ Restrito porque a produção em massa e os mercados de consumo em massa foram restringidos a regiões e setores industriais específicos. Autoritário porque houve o crescimento do emprego industrial, especialmente durante o milagre econômico(1968 a 1973). É inegável o caráter contraditório do fordismo brasileiro, pois, ao mesmo tempo em que a intensa industrialização permitiu acentuada mobilidade social e ocupacional, base do surgimento de trabalhadores organizados, permitiu também, segundo Mattoso (1995, p. 131), baixos salários e formas precárias de trabalho.

Na década de 1980, assiste-se ao fracasso desse modelo brasileiro de desenvolvimento industrial, baseado na orientação ao mercado interno, na intervenção maciça do Estado na economia, na proteção elevada e indiscriminada da indústria nacional, no baixo esforço tecnológico, na substituição de importações e na obtenção de divisas através de crédito externo.

A crise do modelo fordista de desenvolvimento, iniciada nos anos 70 , continua ao longo da década seguinte. Os anos 80 são aqueles em que as economias capitalistas tentaram superar essa crise ajustando-se a uma nova base técnica. A globalização econômica, o pós-fordismo, a terceira revolução industrial surgem em cena.

A terceira revolução industrial, que atinge a economia mundial no final do século XX e início de século XXI, não representa apenas um mero conjunto de mudanças tecnológicas - ela é muito mais do que isto. É um conjunto de mudanças políticas, econômicas, financeiras, culturais, organizacionais e territoriais. No entanto, como alerta Harvey (1994), esse conjunto de mudanças caracteriza um processo de transição rápido, mas ainda não bem entendido do paradigma fordista para um provável regime de acumulação flexível. 
A nova base técnica é caracterizada pelo desenvolvimento da microeletrônica e da informática, da química fina e da biotecnologia. As transformações técnicas também se caracterizam por processos de produção flexíveis, de propósitos múltiplos, poupadores de energia, informatizados e automatizados; pela busca do aperfeiçoamento constante da qualidade dos produtos; pela diminuição do uso de matérias-primas tradicionais e pelo aumento do uso de matérias-primas mais elaboradas; pela significativa redução da incorporação de trabalho não-qualificado e pela valorização do trabalho altamente qualificado.

O modelo japonês é um bom representante desse novo paradigma de produção industrial. As características que se destacam nas práticas japonesas são: equipamentos flexíveis; emprego vitalício e alta qualificação do núcleo de sua força de trabalho; baixos índices de rotatividade; polivalência e rotação de tarefas; predomínio do grupo de trabalho sobre o indivíduo; sistema meritocrático de salários e promoções; sindicatos fracos; linha de demarcação mais difusa entre direção e execução; melhor conhecimento e domínio por parte do trabalhador em relação ao processo global de produção; estratégias de produção baseadas na produção enxuta, em que se elimina o excesso (insumos, espaço, trabalhadores etc.), externalizando e subempreitando tarefas de produção antes concentradas em uma só empresa. ${ }^{19}$

Em oposição à rigidez fordista, a palavra de ordem na terceira revolução tecnológica é flexibilidade, tanto na esfera da produção quanto na esfera da circulação de mercadorias. A flexibilização das relações de trabalho permitiu ao empregador contratar e demitir com mais facilidade, reduzindo as despesas no que respeita aos custos trabalhistas.

As mudanças organizacionais de flexibilização também possibilitaram o surgimento de novas formas de contração, porém sem responsabilidades trabalhistas. A terceirização da força de trabalho surgiu a partir dessas mudanças. A flexibilidade e essas novas formas de organização empresarial estão, de maneira crítica, contribuindo para eliminar mais e mais postos de trabalho e ampliar os índices de pobreza no País. Segundo Tavares (1993), o sistema flexível caracteriza-se por altas taxas de rotatividade, proliferação do trabalho temporário e de tempo parcial, e do trabalho em domicílio.

Existem duas formas de flexibilidade: a quantitativa e a funcional. A primeira está relacionada a níveis de emprego e salários livremente 
negociados no mercado sem a interferência do Estado. A segunda, flexibilidade funcional, está relacionada à utilização do trabalho mais adequada às mudanças impostas pela concorrência, o que significa diminuição dos controles burocráticos e da rigidez na divisão do trabalho impostas pelo antigo modelo fordista.

Este modelo de flexibilização das relações de trabalho traz como conseqüência imediata aos trabalhadores de baixa qualificação e/ou baixa escolaridade sérios problemas de colocação no mercado de trabalho, gerando desemprego, aumento do trabalho informal sem garantias trabalhistas e sociais, precariedade nas condições de vida. Essa realidade produz o aumento da exclusão social que por sua vez torna-se um peso para o Estado e para a sociedade.

Medeiros e Salm (1994) apontam uma ressegmentação do mercado de trabalho: o segmento superior com trabalhadores altamente qualificados, com conhecimentos específicos e acesso às informações; o segmento intermediário com trabalhadores qualificados e semiqualificados das grandes empresas; e, por fim, um segmento inferior com uma grande massa de ocupados em atividades mais desestruturadas, como micros e pequenas empresas e o setor de serviços. Enquanto o segmento superior tem grandes benefícios com a globalização e a flexibilização, o segmento intermediário tem redução de postos de trabalho que afetam, sobretudo, mulheres e jovens. Estes últimos engrossam o segmento inferior, provocando desemprego e queda dos salários. Dessa forma, configura-se a exclusão da produção.

As transformações na economia internacional trazem profundas implicações sobre a economia brasileira. A abundância de matérias-primas convencionais e de mão-de-obra barata do modelo fordista eram vantagens comparativas em relação ao mercado internacional. Hoje, com o consumo de matérias-primas convencionais baixando por unidade produzida e com a independência relativa da produção industrial, estas vantagens competitivas deixaram de existir. ${ }^{20}$ Assim, a economia brasileira não poderá deixar de seguir os passos da nova técnica capitalista. Isto traz complicações para um país que possui uma imensa massa de excluídos do consumo, do emprego e do espaço social.

$\mathrm{O}$ processo de reestruturação produtiva da economia brasileira não é um processo linear e uniforme, mas isto não significa que o Brasil esteja fora deste processo ou que ele seja apenas um movimento esporádico. Para alguns autores, o paradigma fordista ainda não se aprofundou 
no Brasil. No que concerne ao consumo ainda há enormes bolsões de miséria que estão fora do mercado e por este motivo torna-se difícil aprofundar estratégias de segmentação de produtos na área, como, por exemplo, a indústria agroalimentar. Segundo Belik (1994), o Brasil dispõe de um mercado de consumo composto por $20 \%$ da população; pequeno, se comparado a países do Primeiro Mundo.

Conforme a reestruturação produtiva avança, o impacto sobre a estrutura ocupacional brasileira torna-se cada vez mais significativo, resultando no fim de postos de trabalho e atingindo, especialmente, os menos qualificados. Agravam-se assim as condições reais do mercado de trabalho brasileiro.

Como alguns autores já evidenciaram, no período de forte industrialização (1940 a 1980), o Brasil assistiu a uma forte expansão do trabalho regulamentado que, no entanto, não foi capaz de contemplar a totalidade da oferta da força de trabalho.

A partir de 1980, esse quadro agrava-se com a estagnação do PIB, que impediu a expansão do mercado de trabalho formal. Supõe-se, portanto, que a estagnação do mercado de trabalho dos anos 80 esteja relacionada à presença de baixas taxas de crescimento econômico, enquanto a deterioração do mercado de trabalho dos anos 90, provavelmente, está associada a taxas baixas de crescimento econômico. Neste contexto, agrava-se a falta de mobilidade entre os segmentos e consolidase o movimento histórico de exclusão social. ${ }^{21}$

Segundo Cano (1993, p. 32), nas primeiras décadas do século XXI, o mercado de trabalho brasileiro estará acrescido de mais de 25 milhões de adultos postulando vagas ocupacionais urbanas. O problema não é só quantitativo, mas também qualitativo. Na década de 1990, Cano (1993) e Albuquerque (1993) já afirmavam que a exclusão estava associada a baixos níveis de renda e de instrução, assinalando que apenas $40 \%$ da força de trabalho industrial brasileira tinha no mínimo curso primário completo e os $60 \%$ restantes estavam divididos em $30 \%$ de analfabetos plenos e outros $30 \%$ de analfabetos funcionais, ou seja, conseguiam ler, porém eram incapazes de interpretar manuais de trabalho (Velloso, 1994).

Os índices de hoje são ainda mais alarmantes, apesar de passados quase duas décadas. A nova exclusão social, se se pode falar em uma nova forma de exclusão, na realidade intensificou-se, uma vez que associou baixos níveis de renda e de instrução à reprodução de baixos níveis de consumo, insuficientes para a manutenção de condições mínimas e dignas 
de sobrevivência, e, em conseqüência, bloqueou a ascensão profissional, mediante a precária oferta de empregos.

Tem-se como resultado a oferta reduzida de postos de trabalho de baixa qualidade, disputada por um grande contingente de trabalhadores, os quais, geralmente, concorrem a empregos que requerem qualificação abaixo da sua, gerando com isso a ampliação da exclusão do trabalhador do mercado formal de trabalho, apesar de possuir níveis de instrução mais elevados do que no passado.

Apesar de os últimos governos propugnarem os direitos democráticos e sociais dos cidadãos brasileiros, anunciando em campanhas políticas o fim das misérias do país, sabe-se, entretanto, que as melhorias tão propagadas, sobretudo nas áreas de educação, saúde e renda, não se têm concretizado. Contrariamente, verificam-se altos índices de analfabetismo, real e funcional, elevada inflação, desemprego em massa, aumento da pobreza, chegando-se inclusive a estimativas vergonhosas que colocam o Brasil com um dos piores indicadores de exclusão social do mundo se comparado com o conjunto de 175 países, ocupando a $109^{a}$ posição, e, se comparado com 35 países da América Latina, o Brasil ocupa a 28ª posição (Pochmann, 2004).

Percebe-se, portanto, que o quadro de exclusão social no país está intimamente ligado a índices relacionados às áreas de educação, saúde e renda, aumentando-se, segundo pesquisa realizada por Pochmann (2004), a pobreza e a miséria absoluta existentes no Brasil. Em pesquisa realizada pela Fundação Getúlio Vargas (2001), com base em uma análise projetada pela fundação, chegou-se à estimativa de que, na primeira década do terceiro milênio, a pobreza no Brasil atingirá mais de 53 milhões de pessoas e mais de 22 milhões encontrar-se-ão abaixo dessa linha, ou seja, em miséria absoluta. A mesma pesquisa revelou na ocasião (2001) que $46 \%$ das crianças brasileiras, aproximadamente 24 milhões de crianças, eram filhos de trabalhadores que recebiam menos de $\mathrm{R} \$ 80,00$ por mês. Em estimativa, projetou que essa realidade não será diferente no Brasil na primeira década do terceiro milênio.

Diante de tal realidade e sabedores de que a retórica neoliberal não produz mudanças concretas, urge-se desvelar o real e requerer os direitos tão proclamados nos momentos eleitorais, implementando-se projetos que alcancem a população já tão excluída e miserável do país. Educação, saber, cultura são imprescindíveis para tornar o povo mais politizado e mais crítico diante de seus direitos sociais, econômicos, 
políticos e culturais, pois, nas cidades brasileiras, acumula-se uma força de trabalho de baixíssima escolaridade e renda, dedicada a atividades em setores de baixa produtividade que constituem a economia informal urbana, sem condições para pleitear o seu ingresso no mercado formal de trabalho, tampouco sem condições para lutar e requerer uma vida mais digna em uma nova sociedade.

CONSIDERAÇÕES FINAIS: O REFLEXO DESSAS MUDANÇAS NO CONTEXTO SOCIAL BRASILEIRO

Desde a década de 1950 até os nossos dias, elabora-se um discurso político que procura criar, artificialmente, o entendimento do deficiente como sujeito produtivo. Esse discurso, fundamentado na política de bemestar social, sustentada ideologicamente por meio de princípios de oferta plena de empregos e igualdade de direitos sociais a todos os cidadãos, traz em seu bojo a falácia dos dispositivos legais, em que as pessoas com deficiência terão os seus direitos individuais e sociais assegurados, garantidos pelo Estado, como forma de propiciar o bem-estar pessoal, social, político e econômico.

A necessidade da vinculação social por meio do trabalho foi pensada pelo Estado e pelos organismos assistenciais existentes, como forma de criar "pseudo-alternativas" de trabalho para o atendimento dos mais carentes, e, especialmente, das pessoas com deficiência. Inicia-se o período de expansão da rede de atendimento da Educação Especial.

Como já foi mencionado anteriormente, a expansão dessa rede no Brasil concretizou-se por meio de duas formas: pública e privada. Apesar de ela ter-se expandido durante estas últimas décadas, grande parte da população com deficiência não foi por ela absorvida em razão de vários fatores, tais como número reduzido de vagas em relação à sua incidência; pouca atenção às questões educacionais, especialmente à educação de pessoas com deficiência; escassez de verbas destinadas à educação dessa parcela da população; carência de serviços sanitários e de saúde; etc. Assim, ao contrário dos países centrais, onde pelo menos os deficientes mentais, físicos, auditivos e visuais têm garantido o acesso à escolaridade, em nosso país, apesar do discurso e das políticas de inclusão escolar, observa-se ainda hoje a exclusão de grande parcela desse segmento social, haja vista que poucos conseguem ingressar e permanecer na escola, tampouco conseguem desenvolver atividades produtivas. 
Essa situação em que se encontram os países capitalistas, especialmente os de periferia, é resultante do desenvolvimento de políticas neoliberais, modelo econômico que trabalha com noções de pleno uso em economia industrial, baseado em pressupostos teóricos keynesianos. Estes pressupostos teóricos, ao serem absorvidos no campo educacional, passaram a ter como prioridades o desenvolvimento de programas especiais para grupos carentes, compreendendo que as desigualdades são resultantes de fatores acidentais ou da negligência das instituições.

Essa forma de entendimento escamoteia o caráter excludente do Estado junto à população com deficiência, intensificando uma política extremamente desigual de distribuição de renda no país. Para justificar suas ações, o Estado possibilita a proliferação de instituições de nível privado (ONGs), assegurando-lhes forte poder intervencionista na sociedade civil. Essas instituições, apoiadas pelo Estado e marcadas por uma filosofia neoliberal, desenvolvem projetos para a criação de um "sujeito disciplinado"- o deficiente.

Alguns autores acreditam que a pessoa com deficiência, se orientada para atingir o máximo de suas potencialidades e se direcionada para estimulação precoce, poderá competir no mercado formal de trabalho. Esses autores, apesar de lutarem contra a exclusão e a marginalização social dessa parcela da sociedade, alienam-se por completo das mudanças ocorridas hoje no mundo do trabalho e, ao alienarem-se, propõem alternativas de inserção para as pessoas com deficiência, como forma de inclusão social, pautadas em atividades baseadas no modelo taylorista/ fordista de produção, no qual o trabalho do deficiente, de natureza nãoqualificado, operacionaliza-se de forma repetitiva, em que o desempenho de atividades manuais passa a ser visto como um progresso técnico do trabalho da pessoa com deficiência.

Isso significou, em um determinado momento histórico, um marco no desenvolvimento das potencialidades da pessoa com deficiência mental. Entretanto, hoje, a realidade é outra. Essa forma de inserção dos trabalhadores deficientes mentais ao processo de produção capitalista submeteos não a um processo de inclusão social, mas a um modo de exclusão social. Essa chamada "inclusão" dos deficientes mentais ao processo de produção capitalista no mundo social favorece o desenvolvimento das desigualdades e da segregação social, uma vez que os mecanismos de produção valorizavam historicamente mais as operações manuais do que propriamente as operações intelectivas do sujeito responsável por essa ação. 
As atividades produtivas, desenvolvidas historicamente pelas pessoas com deficiência mental, situam-se nos setores agrícolas, industriais, comerciais e em outras atividades voltadas à capacidade desses deficientes em realizar determinadas tarefas. Os trabalhos eram classificados em grupos maiores, denominados "famílias de trabalhos". Esses grupos eram organizados em trabalhos profissionais, administrativos, técnicos, trabalhos de oficina, venda, artesanato especializado, semiespecializado e trabalho manual não especializado (não qualificado).

Neste contexto, essa mão-de-obra "deficiente" é vista como superada e onerosa. Apesar de ela ter sido "adestrada" nos moldes taylorista/fordista, com base no desenvolvimento de tarefas repetitivas, não conseguiu satisfazer plenamente as necessidades desses modelos.

$\mathrm{Na}$ fase atual do capitalismo, verifica-se o esgotamento do modelo de desenvolvimento fordista/keynesiano, emergindo nesse contexto um novo modelo de produção ainda não muito bem definido. Neste novo modelo emergente, o deficiente mental permanece ainda mais segregado e estigmatizado, pois à medida que o próprio mundo do trabalho, já convencionalmente estabelecido por aqueles modelos, não conseguiu contribuir para a constituição social do homem "dito normal", este novo modelo estimula, de forma mais acentuada, o isolamento e a exclusão de quem já estava de fora do sistema produtivo - o deficiente mental.

As transformações ocorridas nesse universo apresentam profundas implicações para as pessoas com deficiência mental. A terceira revolução tecnológica transforma os trabalhadores de pouca qualificação, nesse caso os deficientes, em sujeitos potenciais de trabalho de mão-de-obra inexistente, isto porque a crescente internacionalização da divisão social do trabalho exige por parte do Estado uma mudança operativa na produção crescente de lucros, produzindo a própria ampliação do capital.

Acrescenta-se, ainda, à atualidade do problema colocado, que os recursos financeiros destinados à educação, especialmente à educação das pessoas com deficiência, tiveram uma sensível redução nos últimos anos e com o aumento do desemprego essas pessoas são ainda mais marginalizadas, tendo contra si próprias a "diferença" e/ou a "deficiência" como forma de exclusão social (FERREIRA, 1993).

Diante desse colapso que se reflete também na educação das pessoas com deficiência, inicia-se um novo período de incertezas e de ausência de propostas que garantam a inserção social e a inclusão do deficiente mental no mundo do trabalho. O novo modelo de desenvolvimento capitalista é mais excludente que o antigo modelo fordista. 
Enquanto no fordismo as oportunidades de emprego se generalizavam, a grande massa trabalhadora era incorporada ao mercado de consumo e a industrialização expandia-se pelas diversas regiões do país, nesse novo modelo, o mercado de trabalho exclui o trabalhador, o consumo é seletivo e o crescimento econômico concentra-se regionalmente.

Parafraseando Harvey (1994), a familiarização do deficiente mental na repetição de tarefas constituiu-se em um processo histórico bem prolongado. É necessário se repensar, hoje, criticamente, as propostas educacionais voltadas para o engajamento do deficiente mental no processo de trabalho. A questão é paradoxal, pois não se pode esquecer que o deficiente mental é um trabalhador que, apesar de possuir limitações e especificidades próprias, precisa, como qualquer sujeito social, ser produtor de sua própria existência por meio de sua ação - o trabalho.

\section{ABSTRACT}

This study is a discussion of the vocational training of people with mental disability and the reality of the Brazilian labor market. A question is raised in the context: does the vocational training of people with mental disability promote their inclusion in the regular Brazilian labor market? To respond to this question, the changes imposed by the labor market are discussed, focusing on aspects of the capitalist mode of production, which throughout history has required and demanded new forms of production because of the different industrial and technological revolutions experienced by the society of capital. In addition, questions related to public policy and legislation are discussed as well as the effect of these changes on the social inclusion/exclusion process of these people.

Key words: vocational training; mental disability; social exclusion; work; education.

\section{NOTAS}

1. Ver a esse respeito AMARAL, L. A. Mercado de trabalho e deficiência, p. $127-136$.

2. Essas questões são tratadas em: GOYOS, A. C. A profissionalização de deficientes mentais: estudo de verbalizações de professores acerca dessa questão, 1986; e MANZINI, E. J. Profissionalização de indivíduos portadores de deficiência mental: visão do agente institucional e visão do egresso, 1989.

3. Cf. AMARAL, L. A. Mercado de trabalho e deficiência, p. 133. 
4. Autores como Goyos, Manzini, Carvalho, Balthazar e Miranda (1989) compreendem a profissionalização como alternativa para integração social do portador de deficiência.

5. Sobre esse assunto, ver YOUNG, J. A. Sociedade excludente. Rio de Janeiro: Revan, 2002.

6. Ver a esse respeito RIBAS, J. B. Deficiência: uma identidade social, cultural e institucional construída, 1991, e AMARAL, L. A. Mercado de trabalho e deficiência, 1994.

7. Cf. MARX, K. e ENGELS, F. A ideologia alemã, 1984, p. 25.

8. Ver GOYOS, A. C. A profissionalização de deficientes mentais: estudo de verbalizações de professores acerca dessa questão, 1986. p. 176.

9. A Lei n. 8.213/91 estabelece cotas compulsórias que devem ser respeitadas por empregadores do setor privado que possuírem mais de 100 empregados. Segundo o art. 93, tais empresas privadas devem obedecer às seguintes cotas legais para contratação de pessoas com deficiências habilitadas: de 100 a 200 empregados $-2 \%$ de deficientes habilitados; de 201 a 500 empregados $-3 \%$ de deficientes habilitados; de 501 a 1.000 empregados $4 \%$ de deficientes habilitados; e de 1.001 ou mais $-5 \%$ de deficientes habilitados.

10. Grifo meu.

11. O movimento eugênico, que dominou os Estados Unidos e a Europa influenciando também o Brasil no início do século XX, tinha como fundamento a reprodução e o melhoramento da raça humana.

12. A esse respeito consultar SILVA, Adriane Giugni da. O movimento apaeano no Brasil: um estudo documental (1954-1994), 1995.

13. Ver Lei n. 5.692, de 11 de agosto de 1971.

14. A segunda revolução tecnológica, nascida em meados do século passado, maturada e esgotada entre as décadas de 1960 e 1970, foi caracterizada por inovações no campo da produção de energia elétrica de aço, de produtos químicos pesados, de automóveis.

15. Conceituação mais abrangente de fordismo foi desenvolvida pela Escola Francesa da Regulação, concebida, fundamentalmente, por Michael Aglieta e Robert Boyer.

16. Ver a esse respeito HIRATA, H. Organização do trabalho e qualidade industrial: Notas a partir do caso japonês, 1991; SILVA, E. B. Tecnologia e relações industriais no Brasil no final da década de 80, 1993. 
17. Segundo Oliveira (1988, p. 11), citando dados do Fundo Monetário Internacional, o déficit público dos países industrializados cresceu, em média, de 2,1\% do PIB, em 1972, para 4,9\%, em 1984.

18. Para LIPIETZ (1986, p. 74), o caso brasileiro, assim como o caso de outros países industrializados do Terceiro Mundo, pode ser definido como fordismo periférico. Trata-se de um autêntico fordismo porque se assiste uma forte mecanização resultante de uma cumulação intensiva de capital em setores produtores de bens de consumos duráveis. É periférico porque se mantêm dependente em aspectos tecnológicos aos países centrais e também porque o nível de emprego industrial é garantido por uma demanda formada por uma moderna classe média local, pelo acesso parcial dos trabalhadores fordistas ao mercado e pelas exportações.

19. Ver a esse respeito HIRATA, H. Organização do trabalho e qualidade industrial: notas a partir do caso japonês, 1991; SILVA, E. B. Tecnologia e relações industriais no Brasil no final da década de 80, 1993; SILVA, A. L. G. da \& LAPLANE, M. F. Dinâmica recente da indústria brasileira e desenvolvimento competitivo, 1994.

20. A biotecnologia que proporciona a possibilidade de substituir a natureza em laboratório não avançou como se imaginava no campo de suas aplicações comerciais. Assim, os países produtores de matérias-primas naturais ainda não perderam completamente suas vantagens comparativas.

21. Alguns autores têm associado a maior eficiência da implantação dos novos métodos de organização do trabalho no Brasil a uma maior eqüidade social. “[...] no Brasil muito especialmente, a passagem de um modelo a um outro não pode se fazer [...] senão sobre a base de novos compromissos sociais, tanto dentro como fora da empresa, capazes de assegurar [...] a estabilização e a modernização do assalariado industrial” (CORIAT, 1994, p. 13). “[...] as novas mudanças têm demonstrado que o aumento da eficiência não exige o sacrifício das metas sociais e da liberdade individual. A eficiência pode ser melhor conquistada quando subordinada à eqüidade social, econômica e política" (SILVA, 1993, p. 236). A eficiência dos novos métodos de gestão no Brasil, segundo nosso entendimento, não depende de uma maior eqüidade social, pois com o novo paradigma industrial pós-fordista ou flexível, a iniqüidade, hoje, ganha a forma de exclusão.

\section{REFERÊNCIAS}

ALBUQUERQUE, R. C. de. Pobreza e exclusão social. São Paulo: Nobel, 1993.

AMARAL, L. A. Mercado de trabalho e deficiência. Revista Brasileira de Educação Especial, n. 2, p. 127-136, 1994. 
BELIK, W. Agroindústria e reestruturação industrial no Brasil: elementos para uma avaliação. Revista de Economia, Curitiba, 1994.

BRASIL. Ministério de Educação e Cultura. Lei de Diretrizes e Bases da Educação Nacional. Lei n. 5.692, de 11 de agosto de 1971. In: Reforma do Ensino. Rio de Janeiro: Gráfica Auriverde, 1987.

. Ministério da Educação e Cultura. Centro Nacional de Educação Especial (Cenesp). Associação de Pais e Amigos dos Excepcionais (Apae-SP). Projeto MINIPLAN-APAE 1/73: Habilitação do Deficiente Mental para o Trabalho. São Paulo, 1979.

. Ministério da Educação e Cultura. Planejamento Político Estratégico (1995-1998). Brasília: MEC, 1995.

. Ministério do Trabalho. Secretaria de Formação e Desenvolvimento Profissional. Educação profissional: um projeto para o desenvolvimento sustentado. Brasília: SEFOR, 1995.

Sistema de emprego e educação profissional: implementação de uma política integrada. Brasília: MTb, 1996.

Lei $n$. 7.853, de 24 de outubro de 1989. Dispõe sobre o apoio às pessoas portadoras de deficiência, sua integração social, sobre a Coordenadoria Nacional para Integração da Pessoa Portadora de Deficiência (Corde), institui a tutela jurisdicional de interesses coletivos ou difusos dessas pessoas, disciplina a atuação do Ministério Público, define crimes, e dá outras providências. Brasília: Corde, 1989.

Lei n. 8.213, de 24 de julho de 1991. Dispõe sobre os planos de benefícios da Previdência Social e dá outras providências. Brasília: Previdência Social, 1991.

BRAVERMAN, H. Trabalho e capital monopolista: a degradação do trabalho no século XX. 3. ed. Rio de Janeiro: Guanabara Koogan, 1987.

CANO, W. Reflexões sobre o Brasil e a nova (des)ordem internacional. 2. ed. Campinas: Editora da Unicamp, 1993.

CORIAT, B. Pensar pelo avesso: o modelo japonês de trabalho e organização. Rio de Janeiro: Revan/UFRJ, 1994.

DA ROSS, S. Z. Política Nacional de Educação Especial - Considerações. Cadernos CEDES, São Paulo, n. 23, 1989.

DIEESE. O desemprego e as políticas de emprego e renda. São Paulo: Dieese, 1994.

FERREIRA, J. R. A exclusão da diferença: a educação do portador de deficiência. Piracicaba: Unimep, 1993. 
GOYOS, A. C. A profissionalização de deficientes mentais: estudo de verbalizações de professores acerca dessa questão. 1986. Tese (Doutorado em Educação) - Faculdade de Educação, Universidade de São Paulo.

GOYOS et al. Justificativas para a formação profissional do deficiente mental: revisão da literatura brasileira especializada. Cadernos de Pesquisa, São Paulo, n. 69, mai., 1989. p. 53-67.

HARVEY, D. A condição pós-moderna: uma pesquisa sobre as origens da mudança cultural. São Paulo: Loyola, 1994.

HIRATA, H. Organização do trabalho e qualidade industrial: notas a partir do caso japonês. São Paulo: Edusp, 1991.

INSTITUTO NACIONAL DE ESTUDOS E PESQUISAS EDUCACIONAIS. Educação Especial: A realidade brasileira. Em Aberto, Brasília, ano XIII (60), out./dez. 1993.

JANNUZZI, G. A luta pela educação do "deficiente mental" no Brasil. São Paulo: Cortez/Autores Associados, 1985.

LIPIETZ, A. Mirages et miracles: problèmes de l'industrialisation dans le tiers monde. Paris: Éditions La Découverte, 1986.

MANZINI, E. J. Profissionalização de indivíduos portadores de deficiência mental: visão do agente institucional e visão do egresso. 1989. Dissertação (Mestrado em Educação) - Universdade Federal de São Carlos.

MARX, K.; ENGELS, F. A ideologia alemã. São Paulo: Editora Moraes, 1984.

MATTOSO, J. E. A desordem do trabalho. São Paulo: Scritta, 1995.

MEDEIROS, C. A.; SALM, C. O mercado de trabalho em debate. Novos Estudos, Cebrap, São Paulo, jul., 1994.

OLIVEIRA, F. de. O surgimento do antivalor; capital, força de trabalho e fundo público. Novos Estudos, Cebrap, São Paulo, out., 1988.

POCHMANN, M. et al. (Orgs.) Atlas da exclusão social: a exclusão no mundo. São Paulo: Cortez, 2004.

RIBAS, J. B. Deficiência: uma identidade social, cultural e institucional construída. Integração, Brasília, n. 9, 1991. p. 4-7.

SILVA, A. G. da. O movimento apaeano no Brasil: um estudo documental (1954 - 1994). 1995. Dissertação (Mestrado em Educação) - Faculdade de Educação, Pontifícia Universidade Católica de São Paulo.

. A educação profissional de pessoas com deficiência mental: a história da relação Educação Especial/Trabalho na Apae-SP. 2000. Tese (Doutorado em Educação) - Faculdade de Educação, Universidade de Campinas. 
SILVA, A. L. G. da; LAPLANE, M. F. Dinâmica recente da indústria brasileira e desenvolvimento competitivo. Economia e Sociedade. Campinas: Instituto de Economia/Unicamp, n. 10, 1994.

SILVA, E. B. Tecnologia e relações industriais no Brasil no final da década de 80. In: HIRATA, H. (Org.). Sobre o modelo japonês. São Paulo: Edusp, 1993.

TAVARES, H. M. Complexos de alta tecnologia e reestruturação do espaço. Rio de Janeiro: Instituto de Pesquisa e Planejamento Urbano e Regional/UFRJ, 1993.

TAVARES, M. da C. A desmontagem do Brasil. Brasil Agora, São Paulo, n. 71, jul., 1995.

VELLOSO, J. P. dos R.; ALBUQUERQUE, R. C. de. Modernidade e pobreza: a construção da modernidade econômico-social. São Paulo: Nobel, 1994.

YOUNG, J. A. Sociedade excludente. Rio de Janeiro: Revan, 2002. 